\title{
Measurement Precision Under Repeatability Conditions of a Batch of Sound Power Assessment for Blenders in Reverberation Room
}

\author{
Rodrigo P.B. COSTA-FELIX \\ Laboratory of Ultrasound, National Institute of Metrology, Quality, and Technology (Inmetro) \\ Av. Nossa Senhora das Graças, 50 (Bld 1) - Xerém, Duque de Caxias, RJ, Brazil, ZIP 25.250-020; \\ e-mail: rpfelix@inmetro.gov.br
}

(received September 18, 2015; accepted June 6, 2016)

\begin{abstract}
A set of sound power assessments was performed to determine measurement precision in specified conditions by the comparison method in a reverberation room with a fixed position array of six microphones. Six blenders (or mixers) and, complementary, a reference sound source were the noise sources. Five or six sound power calculations were undertaken on each noise source, and the standard deviation $\left(s_{r}\right)$ was computed as "measurement precision under repeatability conditions" for each octave band from $125 \mathrm{~Hz}$ to $8 \mathrm{kHz}$, and in $\mathrm{dB}(\mathrm{A})$. With the results obtained, values of $s_{r}$ equal $1.0 \mathrm{~dB}$ for $125 \mathrm{~Hz}$ and $250 \mathrm{~Hz}$, $0.8 \mathrm{~dB}$ for $500 \mathrm{~Hz}$ to $2 \mathrm{kHz}$, and $0.5 \mathrm{~dB}$ for $4 \mathrm{kHz}$ and $8 \mathrm{kHz}$. Those can be considered representative as sound power precision for blenders according to the measurement method used. The standard deviation of repeatability for the A-weighted sound power level equals $0.6 \mathrm{~dB}$. This paper could be used for house or laboratory tests to check where their uncertainty assessment for sound power determination is similar or not to those generated at the National Metrology Institute.
\end{abstract}

Keywords: metrology; measurement precision; sound power assessment; reverberation room.

\section{Introduction}

All over the world, noise labelling programs of household appliances have been carried out (for instance EEC, 1986; CONAMA, 1994; HSE, 2001; EPDHK, 2006; NSW, 2010). The basic aim of this kind of programs is to reduce overall environmental noise as a step to improve population's quality of life. In general, noise reduction is achieved indirectly as long as a typical labelling program only informs customers about the noise emitted by an appliance. In most cases, this is done showing its A-weighted sound power level, without imposing any restriction to its commercialisation. Considering that customers have enough information about noise and its implications to human health and comfort, silent products will be more acceptable by them than the noisier ones. It could, hopefully, lead manufactures to reduce the noise emission of their products, in order to let them be more competitive.

On the other hand, once a labelling program is mandatory, a manufacturer could use the label as a marketing tool in case this product has a lowlevel value declaration. As a common rule (IEC, 2006; ABNT, 1998b; JonAsson, Stenhoff, 1992), the level to be declared to a household appliance model is the mean sound power level of some specimens (at least 3) plus an additional amount. This additional amount has the purpose of expressing a reliable value for declaration that shall cover a large range of specimens (more than $95 \%$ is desirable). It takes into account some eventual deviation in its production (as long as only few appliances are tested), and the lack of precision to estimate the sound power output of the noise source (household appliance, in this case), mostly due to the uncertainty of the method and intra- and interspecimens sound output fluctuation during a short or long term experiment.

The amount to be summed that was referred is derived, in a wide sense, from uncertainty. The lowest the amount to be summed, the lowest will be the value to be labelled for a given sort of sound source. Only with uncertainty data completely described it is possible to prevent overestimation while keeping reliable labelling values. A necessary step towards that objective is to assess as comprehensive as possible the measurement precision of a specific kind of sound source under consideration (BAtKo, StęPIEŃ, 2014; BIPM, 2008). Throughout this text, "measurement precision" and 
"specified conditions" will be used as defined in the international vocabulary of metrology (BIPM, 2012), in its item 2.15. The specified conditions for experiments carried out in the work presented herein were as close as possible to repeatability, as the same devices were used in all measurements performed by the same operator and the same instrumentation and reverberation room. However, mainly due to mounting of the system and because all measurement took more than 10 days to be concluded, one could argue that repeatability conditions were not achieved. To use reproducibility, some specified conditions need to be more properly determined. Reproducibility would be a specified condition more properly considered. Even so, the definition of "measurement precision" from the international vocabulary of metrology applies (BIPM, 2012), and "specified condition" as described further is to be considered.

There is a huge amount of literature on repeatability and reproducibility of the determination of sound power, such as in anechoic or hemi-anechoic chambers (PAyne, Simmons, 1996; 2000; PAyne, Hanes, 1993; HANES, 1992) and as in reverberation rooms (Vorländer, RaABe, 1995; Lubman, 1974). Comparisons between intensity and pressure methods have also been studied (MASSACESI et al., 1997; PARIS, TABUEnCA, 2000). Some parameters that could be used in intermediate steps of sound power determination, depending on the method adopted, have been investigated with respect to repeatability (VORLÄNDER, Bietz, 1994; LundeBy et al., 1995).

Despite the existing literature on this subject is vast, some specific noise sources remain unstudied, or at least in some cases their sound power precision was not evaluated. To fully determine the uncertainty in sound power assessment of a given source, it is necessary to use information obtained statistically, e.g. on repeatability and reproducibility (BIPM, 2012 ; ISO, 1985; 1994a). The main goal of this paper is to report some findings obtained in a study of sound power assessment of household appliances under specified conditions. The measurand considered in the present work is sound power of a specific kind of sound source, namely blenders (or mixers). The influence variables were kept the same throughout the measurement scheme to assure repeatability conditions as close as possible. With the results presented herein, it is possible to estimate more precisely the sound power emission uncertainty for this type of noise source. This work complements a contribution to this subject previously presented (COSTA-FELIX, 2006).

\subsection{Brazilian noise-labelling program}

Noise labelling of all models of mixers and blenders commercialised in Brazil became mandatory after national regulation (CONAMA, 1994), following a prede- termined sequence of different types of household appliances. The value to be declared is the (arithmetical, not energy based) mean sound power level of 3 randomly sampled specimens, in $\mathrm{dB}(\mathrm{A})$, plus $3 \mathrm{~dB}(\mathrm{~A})$, which shall correspond to a statically maximum expected power variation of all appliances of that model, with a probability of $95 \%$. The value of $3 \mathrm{~dB}(\mathrm{~A})$ to be summed was not determined after a specific series of experiments, but it was chosen as an overestimated assurance of the $95 \%$ reliability for the declared value.

Sound power level assessments shall be done according to the Brazilian standards (ABNT, 1997; 1998a), which were based on the engineering-grade ISO standards (ISO, 1994b; 2010a; 2010b) and specific test codes (IEC, 2010). Hemi-anechoic or reverberation chambers can be used, as well as the comparison or the direct method. Usually, sound power is firstly determined in 1/1 octave bands, from $125 \mathrm{~Hz}$ up to $8 \mathrm{kHz}$, although this is not mandatory. The final result shall be given in A-weighted sound power level. Either a fixed array of microphones or a continuous path for one microphone can be used.

The Acoustics Testing Laboratory of the Brazilian National Institute of Metrology, Quality and Technology (Inmetro) was responsible for the technical implementation of the noise labelling program (ARAUJO et al., 1995). A method applicable in most of the existing laboratories was chosen for implementation. In this study, the comparison method in reverberation room with fixed array of microphones, as outlined in an international technical standard (ISO, 2010a), was chosen. Although it is not imperative, probably most of the secondary laboratories adopt this method for sound power assessment for blenders and others household appliances.

As part of the implementation of the method, a series of experiments at specified conditions were carried out, and, as it is the aim of this work, it is presented further in Results. The results obtained shall not be confused with uncertainty, but they can be used in a full model for expression of the uncertainty in sound power determination of mixers (COSTA-FELIX, 2006). They are particularly useful for secondary laboratories as an initial estimation of their own repeatability. It is also interesting to notice that the "uncertainty" outlined in the sound power determination ISO standards (ISO, 1994b; 2010a; 2010c) is not the uncertainty as is presently understood (BIPM, 2012), because it deals just with "... standard deviation of reproducibility..." (Table 1 of ISO, 2010a) of generic noise sources.

\section{Material and methods}

\subsection{Measurement method and specified conditions}

Sound power level was determined by the comparison method in a reverberation room, as described 
in (ISO, 2010a). The sound pressure level inside the room was measured with six microphones randomly distributed, all of them more than $\lambda / 2$ apart from each other, from the ceiling, from the floor, from the noise source and from the walls, where $\lambda$ is the wavelength of the centre frequency of the $125 \mathrm{~Hz} 1 / 1$ octave band $(\lambda \cong 1.4 \mathrm{~m})$. Sound pressure level was measured in $1 / 1$ octave band ranging from $125 \mathrm{~Hz}$ to $8 \mathrm{kHz}$ with 64 seconds of duration for each microphone. The sound power level was determined according to Eq. (1), as following:

$$
L_{w}=L w_{R S S}+\left(L_{p}-L p_{R S S}\right)
$$

in which $L_{w}$ is the sound power level of a specific sound source, $L w_{R S S}$ is the sound power level of the reference sound source (previously calibrated), $L_{p}$ is the sound pressure level measured for the specific sound source, and $L p_{R S S}$ is the sound pressure level measured for the reference sound source. One should be aware that the pressure level for both the reference sound source and the device under calibration shall be measured in the same spot consecutively. Equation (1) shall apply for every frequency of interest.

To every set of six spatially distributed sound pressure level measurements, the energy-based mean and the spatial standard deviation $\left(s_{e}\right)$ for all octave bands considered were calculated (see Eq. (2)).

$$
s_{e}=\sqrt{\frac{1}{\left(N_{m}-1\right)} \sum_{i=1}^{N_{m}}\left(\bar{L}_{p}-L p_{i}\right)^{2}},
$$

in which $N_{m}$ is the number of microphones positioned inside the reverberation chamber $\left(N_{m}=6\right), L p_{i}$ is sound pressure level averaged over 64 seconds for each microphone, and $\bar{L}_{p}$ is the energy-base average sound pressure level for all 6 microphones. The spatial standard deviation $s_{e}$ was assessed for each $1 / 1$ octave band of interest in this research ( $125 \mathrm{~Hz}$ to $8 \mathrm{kHz})$. It is worth mentioning that the standard deviation was not computed in an energy-based fashion because the procedure defined in the technical standards demands the statistics to be done as described in Eq. (2) (CostaFELIX, 2006).

All noise sources (blenders and reference sound source) were positioned at the same spot on the floor throughout all measurements. It was not necessary to place the noise sources at more than one position because all $s_{e}$, for all octave bands considered, were lower than $2.3 \mathrm{~dB}$ (as can be observed in Tables 1 and 2), what complies to the technical standard under consideration (ABNT, 1997). The background noise was measured just before every set of measurements. A correction was not applied as for any octave bands the background noise was found more than $15 \mathrm{~dB}$ lower than the mean sound pressure level of each sound source. As part of the specified condition, all equipment was turned off and on between each measuring
Table 1. Maximum spatial standard deviation $\left(s_{e}\right.$, expressed in $\mathrm{dB}$ ) of sound pressure level measurements inside

\begin{tabular}{|c|c|c|c|c|c|c|c|}
\hline \multirow[b]{2}{*}{$\begin{array}{l}\text { Noise } \\
\text { source }\end{array}$} & \multicolumn{7}{|c|}{$1 / 1$ Octave band center frequency } \\
\hline & $\begin{array}{l}\stackrel{N}{\sim} \\
\stackrel{20}{\sim} \\
\stackrel{2}{\sim}\end{array}$ & $\begin{array}{l}\text { N } \\
\text { 足 } \\
\stackrel{2}{N}\end{array}$ & $\begin{array}{l}N \\
\text { N } \\
8 \\
8\end{array}$ & $\underset{\mathbb{A}}{\mathbb{N}}$ & $\frac{N}{N}$ & $\underset{\not}{\stackrel{N}{\mid}}$ & $\underset{\infty}{N}$ \\
\hline Blender \#1 & 2.2 & 2.1 & 1.2 & 0.4 & 0.4 & 0.6 & 0.7 \\
\hline Blender \#2 & 1.8 & 1.7 & 0.7 & 0.4 & 0.6 & 0.4 & 0.5 \\
\hline Blender \#3 & 2.1 & 1.2 & 1.0 & 0.5 & 0.5 & 0.4 & 0.7 \\
\hline Blender \#4 & 2.1 & 0.9 & 0.6 & 1.2 & 0.7 & 0.7 & 0.6 \\
\hline Blender $\# 5$ & 2.1 & 1.4 & 0.4 & 0.3 & 0.8 & 0.8 & 0.4 \\
\hline Blender \#6 & 0.7 & 1.8 & 0.8 & 0.9 & 0.4 & 0.3 & 0.6 \\
\hline B\&K 4204 & 0.5 & 0.6 & 0.3 & 0.3 & 0.2 & 0.2 & 0.3 \\
\hline
\end{tabular}
the reverberation room in 6 measurements.

Table 2. Maximum spatial standard deviation $\left(s_{e}\right.$, expressed in $\mathrm{dB}$ ) of sound pressure level measurements inside

\begin{tabular}{|c|c|c|c|c|c|c|}
\hline \multirow[b]{2}{*}{$\begin{array}{l}\text { Noise } \\
\text { source }\end{array}$} & \multicolumn{6}{|c|}{ Measurement Id } \\
\hline & $\begin{array}{l}\text { \# } \\
\dot{0} \\
\stackrel{0}{0} \\
\sum\end{array}$ & $\begin{array}{l}\text { \# } \\
\dot{\tilde{I}} \\
\stackrel{\tilde{D}}{\mid}\end{array}$ & 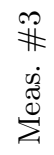 & $\begin{array}{l}\not \\
\# \\
\dot{\mathbb{Z}} \\
\dot{\mathbb{d}}^{2}\end{array}$ & 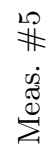 & $\begin{array}{l}0 \\
\# \\
\dot{\Xi} \\
\stackrel{\Xi}{\Xi}\end{array}$ \\
\hline Blender \#1 & 2.2 & 1.6 & 1.5 & 2.2 & 1.7 & 2.1 \\
\hline Blender \#2 & 1.1 & 1.0 & 1.6 & 1.7 & 1.7 & 1.8 \\
\hline Blender \#3 & 1.7 & 2.1 & 2.0 & 2.1 & 2.1 & 2.1 \\
\hline Blender \#4 & 0.9 & 2.0 & 2.1 & 1.2 & 1.1 & 2.0 \\
\hline Blender \#5 & 1.3 & 1.2 & 1.4 & 1.2 & 1.4 & 2.1 \\
\hline Blender \#6 & 1.0 & 1.2 & 1.8 & 0.8 & 1.3 & n.a. \\
\hline B\&K 4204 & n.a. & 0.5 & 0.6 & 0.5 & 0.5 & 0.5 \\
\hline
\end{tabular}
the reverberation room in all $1 / 1$ octave bands.

sequence, and the same operator conducted all measurements.

Before and after a whole measurement, the electrical gain of the measurement setup was observed and adjusted (if necessary) by the aid of a sound calibrator. Between two sets of sound pressure data acquisition, the atmospheric conditions (temperature, relative humidity, and static pressure) were recorded.

Six blenders, each one of a different model, were used in the experiment, named Blender \#1, Blender \#2, etc. Complementary, and for illustrative purpose, a reference sound source was also used as noise source, and its sound power was determined by the comparison method. For each of the seven noise sources (six blenders and a reference sound source), sound power was calculated up to six times. All measurements were performed within ten days by the same operator and with the same measurement system to guarantee repeatability conditions as close as possible. To quantitatively express the repeatability, the stan- 
dard deviation $s_{r}$, as defined in Eq. (3), was calculated

$$
s_{r}=\sqrt{\frac{1}{\left(N_{\text {rep }}-1\right)} \sum_{i=1}^{N_{\text {rep }}}\left(\overline{L_{w}}-L w_{i}\right)^{2}},
$$

in which $N_{\text {rep }}$ is the number of times the sound power was determined in repeatability conditions $\left(N_{\text {rep }}=6\right.$ in this experiment), $L w_{i}$ is sound power level for each repetition, and $\overline{L_{w}}$ is the energy-base average sound power level for all 6 repetitions. The repeatability standard deviation $s_{r}$ was determined for each sound source.

For each 1/1 octave band, the maximum, minimum, and average standard deviations $\left(\bar{s}_{r}\right)$ were computed for all sound sources in this research. The formulae to compute the average standard deviation are disclosed in Eq. (4)

$$
\bar{s}_{r}=\frac{\sum_{i=1}^{N_{\text {source }}}\left(s_{r i}\right)}{N_{\text {source }}}
$$

in which $N_{\text {source }}$ is the number of sound sources used in this research $\left(N_{\text {source }}=6\right.$, i.e., 6 blenders were used in the experiment), $s_{r i}$ is the standard deviation of repeatability for each sound source, as computed in Eq. (3). The reference sound source power values were not computed, as they differ significantly from the blenders output sound power.

Before the first measurement, all blenders worked for at least 10 minutes for electrical and mechanical conditioning. During the test, blenders' containers were filled with $2 / 3$ of their total volume with water. The water temperature should be between $15^{\circ} \mathrm{C}$ and $25^{\circ} \mathrm{C}$ at the beginning of the test, and the final temperature should be less than $50^{\circ} \mathrm{C}$. All appliances were tested at $127 \mathrm{~V} \pm 1 \%$, and $60 \mathrm{~Hz} \mathrm{AC}$. The testing procedure presented above fully complies with all standardised requirements (ABNT, 1997; 1998a).

\subsection{Facilities and measurement system}

Sound pressure levels' measurements were carried out in a reverberation room with volume of $196.0 \mathrm{~m}^{3}$ and total superficial area of $208.3 \mathrm{~m}^{2}$. Before the experiments started, the qualification of the room was performed to each noise source as stated in (ISO, 2010a), Subsec. 4.3. The requirements for that qualification comprise the volume $\left(>40 \mathrm{~m}^{3}\right)$, the absorption coefficient $(<0.20$ for all octave bands of interest), and the volume of the sound source shall be less than $1 \%$ than the total volume of the reverberation room. The reverberation room where the measurements were performed has an internal volume $>40 \mathrm{~m}^{3}$, and the maximum volume of the sound sources weas less than $0.04 \mathrm{~m}^{3}$, i.e., less than $0.02 \%$ of the room's volume.
Sound absorption measurements were previously conducted in the reverberation room, and there it was less than 0.05 for frequencies above $1 \mathrm{kHz}$ and less than 0.10 for frequencies between $125 \mathrm{~Hz}$ and $1 \mathrm{kHz}$.

Six microphones type 4134, six pre-amplifiers type 2619, a multiplexer type 2811, and a frequency analyser type 2133 (all equipment from Brüel \& Kjær, Denmark) made the measurement setup.

A reference sound source type 4204 (Brüel \& Kjær, Denmark) was used as sound power standard and a type 4228 (Brüel \& Kjær, Denmark) piston phone was used for acoustic calibration. Rotation of the reference sound source was observed with a stroboscope type 1546 (GenRad, USA), and the atmospheric conditions were recorded with a thermo-hygrometer type MTH1360 (Minipa, Brazil) and a barometer type UZ0003 (Brüel \& Kjær, Denmark). All equipment had been calibrated less than two years before the complete experiment was finished.

\subsection{Environmental conditions}

The technical standard (ABNT, 1997) presents limits to environmental conditions, which are reported at Table 3. Another international technical standard (ISO, 2010a) is not very objective with respect to fluctuation of atmospheric parameters, as stated in its Subsec. 4.5.

Table 3. Environmental conditions limits, according to (ABNT, 1997).

\begin{tabular}{|l|c|}
\hline & Range \\
\hline Temperature $\left[{ }^{\circ} \mathrm{C}\right]$ & 15 to 30 \\
\hline Relative humidity $[\%]$ & 30 to 70 \\
\hline Static pressure [mbar] & 860 to 1060 \\
\hline
\end{tabular}

Although it is not a requirement (ABNT, 1997), restrictions imposed by the international standard (ISO, 1994b) were adopted to evaluate if temperature and humidity variations during the experiment were significant or not. The maximum allowed variation of the relation $r . h . \times\left(\theta+5^{\circ} \mathrm{C}\right)$, in which $r . h$. is the relative humidity expressed in percentage and $\theta$ is the temperature expressed in degrees Celsius, is $10 \%$ within a single measurement (ISO, 1994b). The variation of this relation was evaluated for inter-measurements atmospheric conditions. In Table 4, maximum and minimum values of temperature, relative humidity, and static pressure observed during all measurements are shown, as well as the maximum, minimum, and percentage variation of the stated relation. During a single measurement, the variations were less than $1^{\circ} \mathrm{C}$ in temperature, $1 \%$ in relative humidity, and $1 \mathrm{mBar}$ in static pressure. 
Table 4. Measurements environmental conditions, in 5 or 6 measurements, where $r . h$. is the relative humidity expressed in percentage and $\theta$ is the temperature expressed in degrees Celsius.

\begin{tabular}{|c|c|c|c|c|c|c|c|c|c|}
\hline & \multicolumn{2}{|c|}{$\begin{array}{c}\text { Temperature } \\
{\left[{ }^{\circ} \mathrm{C}\right]}\end{array}$} & \multicolumn{2}{c|}{$\begin{array}{c}\text { Relat. humidity } \\
{[\%]}\end{array}$} & \multicolumn{2}{c|}{$\begin{array}{c}\text { Static pressure } \\
{[\mathrm{mbar}]}\end{array}$} & \multicolumn{3}{c|}{$r . h . \times\left(\theta+5^{\circ} \mathrm{C}\right)$} \\
\cline { 2 - 10 } & Min. & Max. & Min. & Max. & Min. & Max. & Min. & Max. & variation* \\
\hline All sources & 24 & 26 & 57 & 61 & 1010 & 1013 & 1740 & 1800 & $3.4 \%$ \\
\hline
\end{tabular}

${ }^{*}$ variation $=100 *[($ Max. - Min. $) /$ Min. $]$

\section{Results}

The results are presented as standard deviation of repeatability $\left(s_{r}\right)$. Table 5 shows $s_{r}$ for each blender and for each $1 / 1$ octave band considered, as well as the arithmetic mean $\left(\bar{s}_{r}\right)$. In Table 5 the resulting figures are shown with one or two digits after the coma. Figure 1 depicts maximum and minimum standard deviation values, as well as the energy-based average disclosed in Table 5 for all frequencies and for $\mathrm{dB}(\mathrm{A})$. One shall consider the numbers and curves presented in Table 5 and Fig. 1 as illustrative of possible results of a repeatability study, but not as a standard or rule, and it should be used carefully. Also, the lower values for standard deviation at higher frequencies could be explained by the fact that they are averaged over a wider band.

Standard deviation in those specified conditions for the reference sound source was less than $0.1 \mathrm{~dB}$ (between 0.05 and 0.09) for all octave bands, including in $\mathrm{dB}(\mathrm{A})$. As it is not similar to blenders' results, it was represented neither in Table 5 nor in Fig. 1.

Table 5. Standard deviation of repeatability for each blender $\left(s_{r}\right)$ and energy-based mean standard deviation $\left(\bar{s}_{r}\right)$, expressed both with 1 and 2 figures in $\mathrm{dB}$.

\begin{tabular}{|c|c|c|c|c|c|c|c|}
\hline $\begin{array}{c}\text { Freq. } \\
{[\mathrm{Hz}]}\end{array}$ & Blender \#1 & Blender \#2 & Blender \#3 & Blender \#4 & Blender \#5 & Blender \#6 & $\bar{s}_{r}$ \\
\hline 125 & $\mathbf{2 . 1}(2.08)$ & $\mathbf{0 . 4}(0.44)$ & $\mathbf{1 . 6}(1.55)$ & $\mathbf{1 . 0}(1.02)$ & $\mathbf{1 . 6}(1.63)$ & $\mathbf{0 . 4}(0.43)$ & $\mathbf{1 . 2}(\mathbf{1 . 2 1})$ \\
\hline 250 & $\mathbf{2 . 0}(1.99)$ & $\mathbf{1 . 3}(1.32)$ & $\mathbf{0 . 7}(0.73)$ & $\mathbf{1 . 1}(1.07)$ & $\mathbf{0 . 5}(0.49)$ & $\mathbf{0 . 6}(0.57)$ & $\mathbf{1 . 0}(\mathbf{1 . 0 4})$ \\
\hline 500 & $\mathbf{1 . 3}(1.28)$ & $\mathbf{0 . 4}(0.36)$ & $\mathbf{0 . 5}(0.46)$ & $\mathbf{1 . 2}(1.16)$ & $\mathbf{1 . 0}(1.03)$ & $\mathbf{1 . 2}(1.23)$ & $\mathbf{0 . 9}(\mathbf{0 . 9 3})$ \\
\hline 1000 & $\mathbf{0 . 9}(0.94)$ & $\mathbf{0 . 6}(0.59)$ & $\mathbf{0 . 3}(0.27)$ & $\mathbf{1 . 2}(1.24)$ & $\mathbf{0 . 8}(0.80)$ & $\mathbf{0 . 9}(0.91)$ & $\mathbf{0 . 8}(\mathbf{0 . 8 0})$ \\
\hline 2000 & $\mathbf{0 . 3}(0.35)$ & $\mathbf{0 . 6}(0.56)$ & $\mathbf{0 . 3}(0.31)$ & $\mathbf{0 . 6}(0.63)$ & $\mathbf{1 . 4}(1.41)$ & $\mathbf{0 . 6}(0.59)$ & $\mathbf{0 . 7}(\mathbf{0 . 6 5})$ \\
\hline 4000 & $\mathbf{0 . 6}(0.62)$ & $\mathbf{0 . 9}(0.92)$ & $\mathbf{0 . 5}(0.48)$ & $\mathbf{0 . 4}(0.39)$ & $\mathbf{0 . 3}(0.26)$ & $\mathbf{0 . 4}(0.43)$ & $\mathbf{0 . 5}(\mathbf{0 . 5 2})$ \\
\hline 8000 & $\mathbf{0 . 6}(0.62)$ & $\mathbf{0 . 4}(0.41)$ & $\mathbf{0 . 7}(0.70)$ & $\mathbf{0 . 4}(0.42)$ & $\mathbf{0 . 4}(0.45)$ & $\mathbf{1 . 2}(1.20)$ & $\mathbf{0 . 6}(\mathbf{0 . 6 3})$ \\
\hline $\mathbf{d B}(\mathbf{A})$ & $\mathbf{0 . 6}(\mathbf{0 . 5 5})$ & $\mathbf{0 . 5}(\mathbf{0 . 5 0})$ & $\mathbf{0 . 2}(\mathbf{0 . 1 9})$ & $\mathbf{0 . 7}(\mathbf{0 . 7 0})$ & $\mathbf{0 . 9}(\mathbf{0 . 9 3})$ & $\mathbf{0 . 5}(\mathbf{0 . 4 5})$ & $\mathbf{0 . 6}(\mathbf{0 . 5 6})$ \\
\hline
\end{tabular}

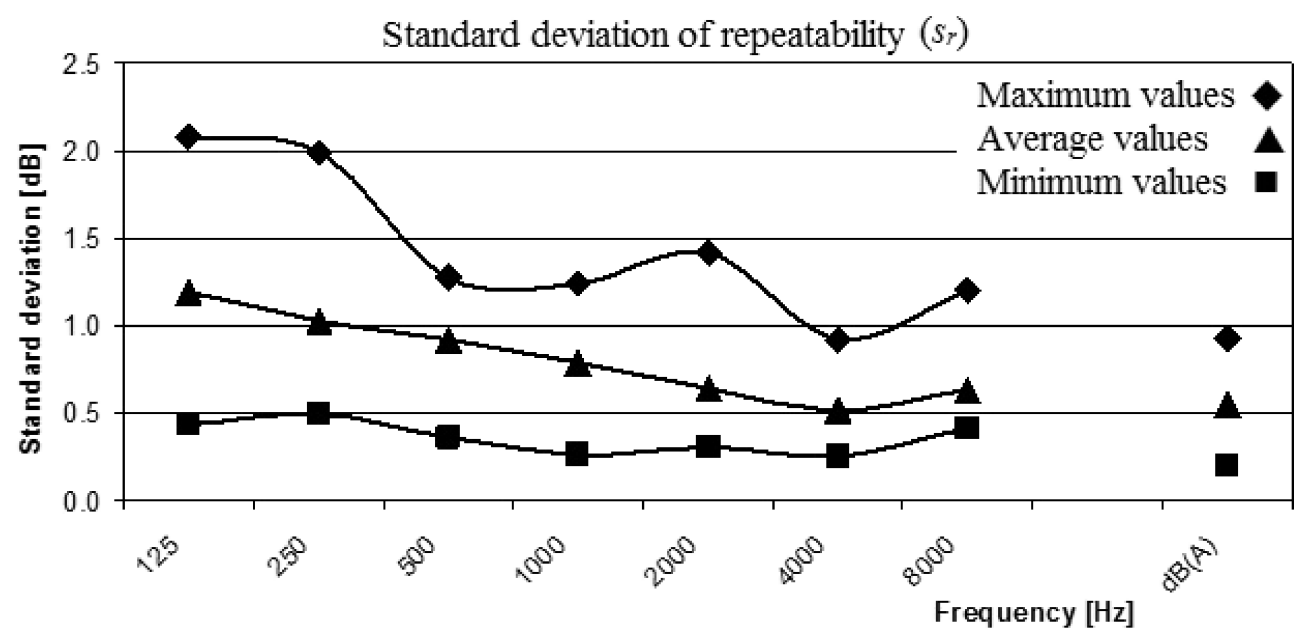

Fig. 1. Maximum ( $)$, minimum ( $\mathbf{\square})$, and energy-based mean $s_{r}(\boldsymbol{\Lambda})$ of all blenders. 


\section{Discussion}

Measurement precision assessment, as internationally defined (BIPM, 2012), is a necessary step towards a full uncertainty declaration. Naturally, it depends on many factors, including instrumentation and operator's ability and experience. Nevertheless, the results stated herein could be used for any secondary laboratory as a guide when they are preparing their uncertainty budget. Of course, it is not the ultimate result concerning the subject, but a fruitful source of information, instead.

Figure 1 and Table 5 are the most important results to be considered. It is clear that a general rule or formula would not be useful to sound power levels precision determination for a particular sound source. Even in a single source type, blenders in this case, spread of standard deviation can be found. Repeatability of power determination is affected by sources like the geometry of the sound source, spectral components in its noise emission, noise coupling to measurement environment, or even measuring system's characteristics. All their effects are experimentally proved. Nevertheless, a general behaviour as can be observed in Fig. 1, is a trend to lower standard deviation at higher frequencies for this particular sound source. One possible reason is that the reverberation room used produces a better coupling with blenders at higher frequencies. It is important to stress, however, that the reverberation room used was qualified according to international standards (ISO, 1994b; 2010a) for the measurement, even for frequencies as low as $100 \mathrm{~Hz}$. An exception was found in blender \#5. This device has a remarkable high standard deviation for $2000 \mathrm{~Hz}$, what could be related to a particular prominent fluctuation in its sound power emission in that frequency if compared with other blenders. However, regarding power spectra, no strange peak for that blender has been found. As measurements were done in $1 / 1$ octave band, an eventually high pure tone could have been averaged, consequently hiding and losing important information. Once more, it reinforces the necessity of determination of measurement precisions (under repeatability and reproducibility, if possible) for each and every sound source prior to a complete uncertainty calculation regarding sound power emission. For instance, blender \#5 would present a larger uncertainty at $2000 \mathrm{~Hz}$ than the other appliances measured for this work.

Comparing the uncertainty expression previously presented (Costa-FELIX, 2006), one can observe that both uncertainties sources (Type B and measurement precision) are of the same magnitude, mainly above $500 \mathrm{~Hz}$. So, differently from what was considered in former times, both sources of uncertainty should be taken into account for a better uncertainty assessment. Hence, Sound Power Level assessment of household ap- pliances can be more precise with respect to values used for labelling purposes, after the work presented in this paper.

\section{References}

1. ABNT (1997), ABNT NBR 13910-1:1997 - Test guidelines for the determination of acoustic noise of household and similar electrical appliances - Part 1: General requirements [in Portuguese], Brazilian Association of Technical Standards (ABNT), São Paulo, Brasil.

2. ABNT (1998a), ABNT NBR 13910-2-3:1998 - Test guidelines for the determination of acoustic noise of household and similar electrical appliances - Part 2: Particular requirements for blenders [in Portuguese], Brazilian Association of Technical Standards (ABNT), São Paulo, Brasil.

3. ABNT (1998b), ABNT NBR 13910-3:1998 - Test guidelines for the determination of acoustic noise of household and similar electrical appliances - Part 3: Procedure for determining and verifying declared noise emission values [in Portuguese], Brazilian Association of Technical Standards (ABNT), São Paulo, Brasil.

4. Araújo M.A.N., Azevedo J.A., Medeiros S. (1995), The Brazilian Noise Labeling Program, International Conference on Noise Control Engineering, Newport Beach, 1445-1449.

5. Batko W.M., Stępień B. (2014), Type A Standard Uncertainty of Long-Term Noise Indicators, Archives of Acoustics, 39, 1, 25-36.

6. BIPM (2008), BIPM/JCGM100:2008, Evaluation of Measurement Data - Guide to the Expression of Uncertainty in Measurement, Genéve.

7. BIPM (2012), BIPM/JCGM200:2012, The International Vocabulary of Metrology, Basic and General Concepts and Associated Terms (VIM), BIPM, IEC, IFCC, ILAC, ISO, IUPAC, IUPAP and OIML, pp. 90.

8. CONAMA (1994), National Council of Environment, CONAMA 020/94, Brasil.

9. Costa-FÉlix R.P.B. (2006), Type B uncertainty in sound power measurements using comparison method, Measurement, 39, 2, 169-175.

10. EEC (1986), Council Directive 86/594/EEC of 1 December 1986 on airborne noise emitted by household appliances, Official Journal of the European Communities, No. L 344, 06DEC1986.

11. EPD-HK (2006), A concise guide to the noise control ordinance, Environmental Protection Department of Hong Kong (EPD-HK), 9th Edition, APR2006.

12. HANES P. (1992), Measurement uncertainties in the determination of machinery sound power levels, Euronoise 92, Book 2, 285-291.

13. HSE (2001), Noise emission in the environment by equipment for use outdoors (NEEEOR), Guidance notes on the UK Regulations, 1st Edition, JUN2001. 
14. IEC (2006), IEC 60704-3:2006 - Household and similar electrical appliances - Test code for the determination of airborne acoustical noise - Part 3: Procedure for determining and verifying declared noise emission values, International Electrotechnical Commission, Geneva, Switzerland.

15. IEC (2010), IEC 60704-1:2010 - Household and similar electrical appliances - Test code for the determination of airborne acoustical noise - Part 1: General requirements, International Electrotechnical Commission, Geneva, Switzerland.

16. ISO (1985), ISO 7574-2:1985 - Acoustics - Statistical methods for determining and verifying stated noise emission values of machinery and equipment - Part 2: Methods for stated values for individual machines, International Organization for Standardization, Geneva, Switzerland

17. ISO (1994a), ISO 5725-2:1994 - Accuracy (trueness and precision) of measurement methods and results Part 2: Basic method for the determination of repeatability and reproducibility of a standard measurement method, International Organization for Standardization, Geneva, Switzerland.

18. ISO (1994b), ISO 3743-2:1994 - Acoustics - Determination of sound power levels of noise sources using sound pressure - Engineering methods for small, movable sources in reverberant fields - Part 2: Methods for special reverberation test rooms, International Organization for Standardization, Geneva, Switzerland.

19. ISO (2010a), ISO 3743-1:2010 - Acoustics - Determination of sound power levels of noise sources - Engineering methods for small, movable sources in reverberant fields - Part 1: Comparison method for hard-walled test rooms, International Organization for Standardization, Geneva, Switzerland.

20. ISO (2010b), ISO 3744:2010 - Acoustics - Determination of sound power levels of noise sources using sound pressure - Engineering method in an essentially free field over a reflecting plane, International Organization for Standardization, Geneva, Switzerland.

21. Jonasson H.G., Stenhoff A. (1992), Declaration and verification of noise emission values, Interna- tional Congress on Noise Control Engineering, Toronto, Canada, 1245-1248.

22. Lubman D. (1974), Precision of reverberant sound power measurements, J. Acoust. Soc. Am., 56, 2, 523533.

23. Lundeby A., Vigran T.E., Bietz H., Vorländer M. (1995), Uncertainties of Measurements in Room Acoustics, Acta Acustica united with Acustica, 81, 344-355.

24. Massacesi A., Paone N., Rossi G.L., Tomasini E.P. (1997), Uncertainty and compatibility analysis of acoustics power determination by intensity and pressure measurement techniques, XIV Congresso Brasileiro de Engenharia Mecânica, Bauru, SP, Brasil.

25. NSW (2010), NWS Department of Environment, Climate Change and Water for the Working Group on Noise Labelling, Australian and New Zealand Noise Labelling and Limit Scheme - Recommendations for Portable Equipment, MAY2010.

26. Paris J.L., TABUenca B.S. (2000), Comparison of the noise level of a washing machine measured by two methods: ISO 3744 and ISO 9614, 7th Int. Congress on Sound and Vibration, Garmisch, Germany, 2511-2518.

27. Payne R.C., Hanes P. (1993), An investigation of measurement uncertainties in the determination of machinery sound power levels, International Congress on Noise Control Engineering, 329-334.

28. Payne R.C., Simmons D.J. (1996), Measurement uncertainties in the determination of the sound power level of machines, International Congress on Noise Control Engineering, Liverpool, Book 5, 2713-2718.

29. Payne R.C., Simmons D.J. (2000), Assessment of reproducibility uncertainties for use in international standards on the determination of sound power, National Physical Laboratory, UK, Report CMAM 51, p. 103.

30. Vorländer M., Bietz H. (1994), Comparison of Methods for Measuring Reverberation Time, Acustica, 80, 205-214.

31. Vorländer M., RaAbe G. (1995), Calibration of reference sound sources, Acustica, 81, 247-263. 